\title{
Small and Medium Enterprise Growth Index: A New Tool for Monitoring the State of the Small and Medium Business Sector in Russia ${ }^{1}$
}

\author{
A. O. Alekhnovich ${ }^{a}$ *, L. L. Anuchin ${ }^{a}$, and A. O. Akhiev ${ }^{a}$ \\ ${ }^{a}$ Stolypin Institute for the Economy of Growth, Moscow, Russia \\ *e-mail: alekhnovich@gmail.com \\ Received January 11, 2021; revised January 21, 2021; accepted February 16, 2021
}

\begin{abstract}
The article presents the Small and Medium Enterprise Growth Index (SMEs), developed by the Stolypin Institute for the Economy of Growth based on the data of PAO Sberbank. The tool proposed by the authors allows not only to carry out operational monitoring of the state of the SME sector, but also to assess the effectiveness of state policy aimed at developing the SME sector, including with the aim of designing further measures to support it. In the context of a pandemic and sanitary and epidemiological restrictions, according to the results of the 1st-3rd quarters of 2020, the index showed moderate growth in the SME sector, close to "stagnation" ( +5.8 p.). At the same time, the growth of the index relative to the 2 nd quarter of 2020 , during which the decline in business activity was maximum, amounted to $+1 \mathrm{p}$.
\end{abstract}

Keywords: big data, SME sector, economic recovery, public policy effectiveness, COVID-19, public administration

DOI: $10.1134 / \mathrm{S} 107570072104002 \mathrm{X}$

Preconditions for the emergence of new tools for assessing the state of the small and medium business sector in Russia. In accordance with the main strategic documents ${ }^{1}$ adopted in Russia, small and medium enterprises (hereinafter referred to as SMEs) are considered as one of the factors of innovative development and improvement of the sectoral structure of the economy, as well as ensuring a consistently high level of employment [1]. The goals were set: by 2030, to increase the number of people employed in small and medium businesses, including individual entrepreneurs and self-employed, to 25 million people [2]; to ensure the growth of the share of SMEs in GDP twofold from 20 to $40 \%$ [1]. Nevertheless, over the past five years, the indicators characterizing the development of the SME sector have not increased.

Among the key constraints to the growth of the SME sector is the use of targeted measures of state support, similar to those for large enterprises, as a result, only a small part of them were able to use the proposed tools.

\footnotetext{
${ }^{1}$ Decree of the President of the Russian Federation, On the National Development Goals of the Russian Federation for the Period until 2030, (2020), the national project, Small and Medium Businesses and Support for Individual Entrepreneurial Initiative (2018), Strategy for the Development of Small and Medium Businesses in the Russian Federation for the Period until 2030, (2016).
}

The state policy in the sphere of development of small and medium businesses in general is assessed as insufficiently effective and uncoordinated, the resources provided within the framework of support measures are limited [3]. The current monetary policy as a whole hinders the development of this sector of the economy; SMEs lack special refinancing instruments [4]. In addition, at the regional level, senior officials responsible for achieving targets for the development of the SME sector cannot influence the volume, conditions and procedure for spending funds included in the national project "Small and Medium Businesses and Support for Individual Entrepreneurial Initiative" [5].

To ensure the growth of the SME sector, it is necessary to implement systemic support measures aimed at changing the conditions for doing business, as well as to change the approach to state policy in the field of small and medium businesses, identifying priority sectors for its development [6]. However, until recently, it was virtually impossible to assess the SME sector using official statistics tools, as well as to determine the effect of the implementation of systemic support measures in relation to SMEs [7]. For example, Rosstat uses both selective (monthly/quarterly) and continuous observations (once every 5 years) to assess the SME sector. In selective observation, a 20 percent stratified random sample is used with the subsequent dissemination of the data to the general population of 
small enterprises. However, taking into account the long time for processing the results (for selective observations, four months, for continuous observations, 1.5 years), it was impossible to obtain prompt and accurate information on the dynamics of indicators characterizing the state of the SME sector.

At the same time, as a result of the development of technologies for collecting, processing and storing information today in Russia, by analogy with other countries, it is possible to create a new environment of trust between the business community and government bodies on the basis of mutually linked, most prompt and reliable big data. Among the sources of these data are both traditional data from Rosstat, the Federal Tax Service, the Federal Customs Service, social funds, and new ones including data from the banking system, commercial platforms, etc. Big data can make it possible to assess not only the state of the SME sector in terms of business size, activities, constituent entities of the Russian Federation and municipalities, but also the effectiveness of state policy in order to further design of measures of state support aimed at the development of the SME sector.

The use of big data in the framework of overcoming the socio-economic consequences of the pandemic of the novel coronavirus infection covid-19: world practice. With the spread of the new coronavirus infection and the introduction of restrictive measures, government authorities and the expert community began to consider big data as a tool not only for tracking and preventing the spread of the disease [8,9], but also for prompt and accurate monitoring of the state of the economy $[10,11]$.

In many ways, the development of technologies for collecting, processing and storing big data before the start of the pandemic was associated with the need of the largest companies to improve the quality of developing business strategies, analyzing consumer demand and searching for new sales markets. With the onset of the pandemic, the demand for data increased due to the need to respond quickly to restrictive measures and a decrease in consumer demand.

At the same time, given the growing demand for big data and analytics based on it, the largest companies began to implement their developments for the purposes of both other companies and government [12]. According to McKinsey, the development of big data technologies during a pandemic can increase the added value created in the economy from 9.5 trillion to 15.4 trillion dollars per year, while the greatest demand for big data will be provided by such sectors of the economy as trade (about 600 billion dollars), transportation and storage (about 420 billion dollars), tourism (about 390 billion dollars) and public administration (about 350 billion dollars per year) [13].

In fact, government authorities, within the framework of monitoring the state of the economy, developing forecasts and adjusting government policies, are paying more and more attention not only to traditional sources of statistical data, but also to the administration of data, including data from private companies [14].

Development of tools for monitoring the state of the economy in Russia: using banking statistics to assess the state of the SME sector. As part of assessing the state of the SME sector in Russia during the pandemic of a new coronavirus infection in November-December 2020, the Stolypin Institute for the Economy of Growth presented the first issue of the SME Growth Index based on the banking statistics of Sberbank.

The SME Growth Index (hereinafter referred to as the Index) is calculated quarterly for all constituent entities of the Russian Federation (except for the Republic of Crimea and Sevastopol) in which Sberbank operates.

In accordance with the methodology for calculating the Index values, the following indicators are used:

-Data of banking statistics on the state of the SME sector (change in the average volume of receipts to the current account of one SME entity; change in the number of jobs per one SME entity; change in the volume of payroll fund for SMEs per employee).

-Data on the volume of consumer spending on goods and services based on data on transactions performed using payment cards are used for reference.

- Survey indicators (a survey of entrepreneurs regarding changes in factors affecting doing business) are planned to be implemented at the second stage.

- Statistical indicators based on the data of the register of SMEs of the Federal Tax Service (change in the number of SMEs; change in the number of employees employed by SMEs; change in the number of newly registered microenterprises) are used for reference.

-Data on the sectoral structure of the SME sector of Rosstat are used for reference.

Statistical indicators used in calculating the Index values include:

1. Change in receipts to settlement accounts of SMEs in terms of one SME entity, with a weight of 0.2. The average volume of receipts to the settlement accounts of one SME entity is calculated as the ratio of the total volume of receipts to the settlement accounts of SME entities on executed payment orders for the reporting period to the number of SME entities with at least one similar receipt for the reporting period.

2. Change in the volume of payroll fund for SMEs per employee, with a weight of 0.4 . The volume of SME payroll fund per employee is calculated as the ratio of the total payroll fund for all SME entities for the reporting period to the number of unique individuals with salaries from SMEs for the reporting period.

3. Change in the number of individuals with salary payments per one SME entity, with a weight of 0.4. The number of individuals with salary accruals per one SME entity is calculated as the ratio of the number of 


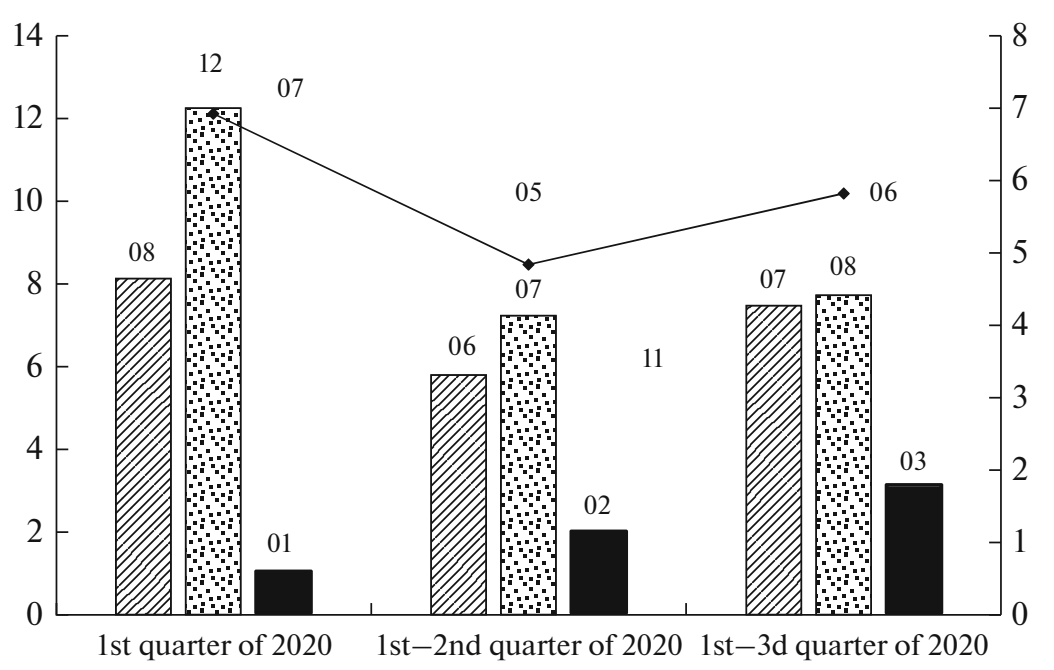

Fig. 1. Dynamics of values of indicators of the SME Growth Index, Index (p.), reporting period to the same period last year: $\square$ Revenue per one enterprise; $\otimes$ payroll fund per one employed; $\boldsymbol{\square}$ number of employees per one enterprise; $-\bullet-$ final index (right scale).

unique individuals with salary accruals from SME entities for the reporting period to the number of SME entities with at least one similar receipt for the reporting period.

To ensure comparability of the results of the development of the SME sector, all constituent entities of the Russian Federation were divided into four groups. The first group of regions includes Moscow, Moscow oblast and St. Petersburg (more than 300 thousand SME entities), the second group of regions 20 constituent entities of the Russian Federation (from 300 thousand to 67 thousand SME entities), the third group 23 constituent entities of the Russian Federation (from 67 thousand to 40 thousand SME entities), and the fourth group 37 constituent entities of the Russian Federation (up to 40 thousand SME entities).

At the first stage, the Index values are calculated for each of the three indicators (revenue per one SME; payroll fund per one employed and the number of employees per one SME) in terms of the constituent entities of the Russian Federation.

The value of each indicator of the Index is considered the cumulative total for the period (for example, the 1st quarter of 2020 to the 1st quarter of 2019 or the 1st-2nd quarter of 2020 to the 1 st-2nd quarter of 2019 , etc.) and is calculated as the ratio of the value for the reporting period to the previous one minus one, multiplied by 100 . As a result of the calculation by periods, the Index smooths out seasonal deviations and reveals the main trends in the development of SMEs relative to the same period last year.

At the second stage, based on the obtained values of each of the three indicators of the Index, converted to a scale from -50 to 50 , a summary value of the
Index is formed for each constituent entity of the Russian Federation as follows:

SME Growth Index $=\Delta$ revenue per $\operatorname{SME}(\%) \times 0.2$

$+\Delta$ volume of payroll fund per 1 employed $(\%) \times 0.4$ $+\Delta$ number of jobs per $\operatorname{SME}(\%) \times 0.4$.

The Index value for Russia is the average value of the Index for all constituent entities of the Russian Federation.

Based on the results of the analysis for the 3 rd quarter of 2020 (Fig. 1), the Index amounted to +5.8 p., while the increase relative to the 2nd quarter of 2020 , during which the decline in business activity was maximum, amounted to $+1 \mathrm{p}$.

The key factors behind the growth of the Index in the 3 rd quarter in relation to the 2nd quarter of 2020 include the following.

The average revenue growth per SME amounted to $+5.9 \%$ compared to the 2 nd quarter, possibly due to the deferred demand and the lifting of restrictions caused by the coronavirus pandemic [15]. Enterprises in the SME sector managed to increase the average volume of revenue per enterprise by 336 thousand rubles relative to the previous two quarters.

The growth in the average volume of payroll fund per one employed $(+4.2 \%$ versus the 2 nd quarter) may be associated with the "whitewashing" of the SME sector due to a decrease in contributions to nonbudgetary funds (load on payroll fund) from 30 to $15 \%$. The salaries of SME employees following the results of the 3 rd quarter increased on average by 1154 rubles $[16,17]$.

There was growth in the average number of jobs per one enterprise $(+1.2 \%$ versus the 2 nd quarter): in gen- 
Table 1. Dynamics of the Growth Index indicators by groups of SMEs in the 3rd quarter of 2020

\begin{tabular}{|c|c|c|c|c|c|c|}
\hline $\begin{array}{c}\text { SME } \\
\text { category }\end{array}$ & $\begin{array}{l}\text { Revenue } \\
\text { per one } \\
\text { SME, p. }\end{array}$ & $\begin{array}{l}\text { Payroll fund } \\
\text { per one } \\
\text { employed, } p \text {. }\end{array}$ & $\begin{array}{c}\text { Number } \\
\text { of employed } \\
\text { per one SME, } \\
\text { p. }\end{array}$ & $\begin{array}{l}\text { Data on revenue per } \\
\text { one SME, for the } 3 \mathrm{rd} \\
\text { quarter of } 2020, \text { rubles } \\
\text { (increase, } \% \text { to the } 2 \text { nd } \\
\text { quarter of } 2020 \text { ) }\end{array}$ & \begin{tabular}{|} 
Data on payroll fund \\
per 1 SME, for the \\
period per month, \\
rubles (increase, $\%$ to \\
the 2nd quarter of 2020)
\end{tabular} & $\begin{array}{l}\text { Data on the number } \\
\text { of employed per } 1 \mathrm{SME} \text {, } \\
\text { people (increase, } \\
\% \text { to the } 2 \text { nd quarter } \\
\text { of } 2020 \text { ) }\end{array}$ \\
\hline Micro & 7.2 & 6.4 & 0.5 & $\begin{array}{c}4280058 \\
(+5.1)\end{array}$ & $\begin{array}{l}27953 \\
(+1.9)\end{array}$ & $\begin{array}{c}3.2 \\
(-0.9)\end{array}$ \\
\hline Small & 10.8 & 6.9 & 7.3 & $\begin{array}{c}47441068 \\
(+5.6)\end{array}$ & $\begin{array}{c}37506 \\
(+3)\end{array}$ & $\begin{array}{l}37.1 \\
(+1)\end{array}$ \\
\hline Medium & 10.2 & 5.9 & 3.7 & $\begin{array}{c}220728400 \\
(+7.8)\end{array}$ & $\begin{array}{l}39262 \\
(+4.1)\end{array}$ & $\begin{array}{c}153.8 \\
(+0.5)\end{array}$ \\
\hline
\end{tabular}

Source. Calculations of the Stolypin Institute for the Economy of Growth.

eral, the number of jobs has not changed and amounted to about 6 units.

The positive trend following the results of the 3rd quarter in the SME sector was created through the implementation of the main package of measures to support the SME sector in the 2nd quarter of 2020. Due to the fact that in the 4th quarter no new support measures were introduced, and new restrictive measures were implemented in most regions of Russia, by the end of the year it is expected that the number of people employed in the SME sector and the payroll fund will not significantly increase.

In the 3rd quarter of 2020, an increase in the Index indicators (Table 1) is observed in all categories of enterprises, while the largest increase in revenue and the number of employees in one SME are traced among small and medium enterprises. In fact, even taking into account the introduced restrictions, SMEs in 2020 tried to preserve employment and wage rates as much as possible.

Nevertheless, in the sectoral context (Table 2), the dynamics of the main indicators of the Index are not positive in all cases. Certain industries, the demand for which either did not decrease or decreased slightly, increased in all three indicators of the Index, however, enterprises in a number of industries, despite the increase in revenue, are reducing their staff, which is caused by negative expectations for future periods.

Among the most affected sectors of the economy: education ( -5.8 p.), activities in the field of culture, sports, leisure and entertainment $(-1.7$ p.), financial and insurance activities $(+0.6$ p.), while the largest decrease in revenue was observed in SMEs operating in the field of culture and sports $(-13 \mathrm{p}$.), hotels and restaurants $(-11.1$ p.) and educational organizations (-7.3 p.).

In terms of groups of regions (constituent entities of the Russian Federation) (Fig. 2), the largest increase in the Index values can be traced in the 4th group, where SMEs are concentrated to a lesser extent. If the 1st group (Moscow, Moscow oblast, St. Petersburg), according to the results of the 1st quarter, were the second highest, then as a result of the restrictions imposed by the 3rd quarter of 2020, the SME sector in this group showed the worst results, primarily due to a weak increase in the number of employed in SMEs and a low increase in revenue per one SME. It also follows from this that the restrictive measures introduced in the 2 nd quarter of 2020 to a greater extent had a negative impact on the regions with the highest concentration of SME entities.

Development potential of the SME growth index as a tool to improve the efficiency of public administration. The results of the first issue of the Index were presented in November-December 2020 at expert discussions in 21 constituent entities of the Russian Federation. The discussions were attended by deputy heads of the constituent entities of the Federation, heads and deputy heads of regional departments responsible for economic development in the region, representatives of regional branches of PAO Sberbank, heads of business associations, business ombudsmen, as well as representatives of the business community. The total number of participants in expert discussions is 589 people.

During the discussions, the participants generally confirmed the relevance and effectiveness of the Index as a tool for monitoring the assessment of the state of the SME sector and public policy measures in relation to this sector. Most constituent entities of the Russian Federation also noted that the Index indicators coincide with the real situation that developed in the regions.

Among the key benefits of the Index, meeting participants cited the following:

-The Index data are as prompt as possible, they can be provided almost online, which greatly distinguishes them from Rosstat data, which provides data with a delay from months to a year, depending on the indicator.

-The Index data cover more than half of all SME entities, which makes it possible to accurately assess 


\begin{tabular}{|c|c|c|c|c|c|c|c|c|c|c|c|c|}
\hline 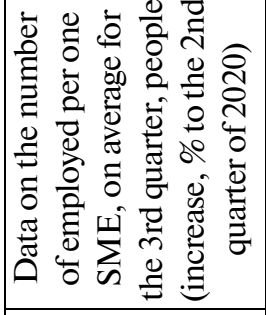 & 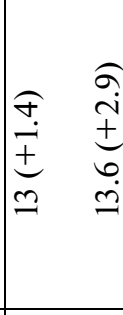 & $\begin{array}{l}\overparen{a} \\
\stackrel{i}{I} \\
a \\
\dot{\infty}\end{array}$ & $\underset{\substack{\tilde{I} \\
\dot{I}}}{\stackrel{\sigma}{I}}$ & $\begin{array}{l}n \\
\tilde{0} \\
+ \\
n \\
n\end{array}$ & $\begin{array}{l}\hat{n} \\
0 \\
1 \\
a \\
\dot{n}\end{array}$ & 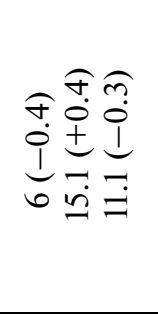 & 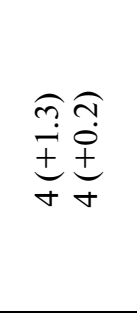 & 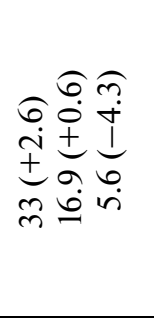 & 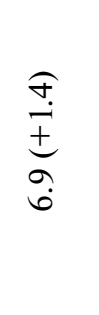 & 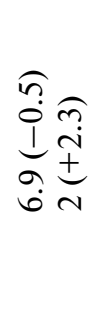 & 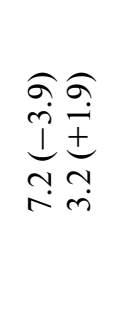 & 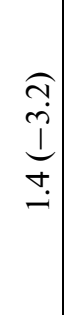 \\
\hline 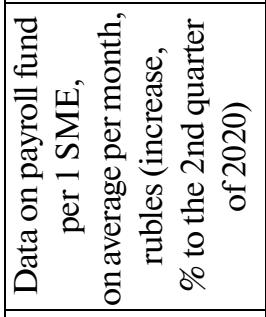 & 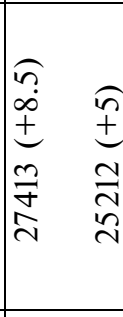 & 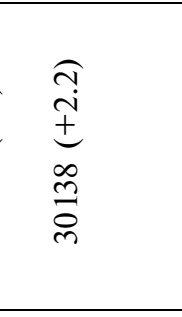 & 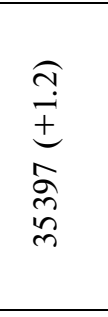 & 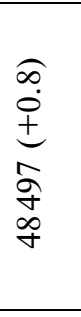 & 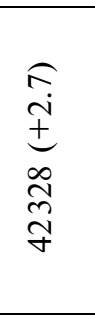 & 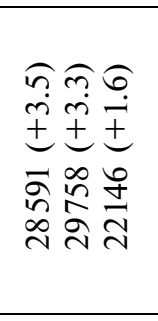 & 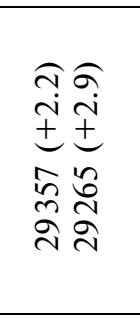 & 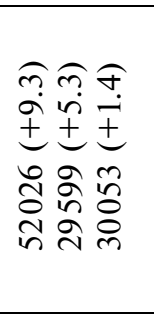 & $\begin{array}{l}\text { T } \\
\pm \\
\infty \\
\infty \\
\infty \\
2\end{array}$ & 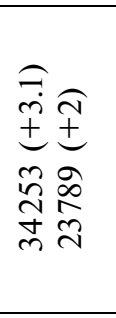 & 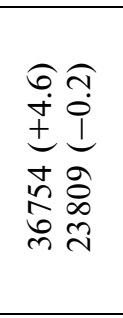 & 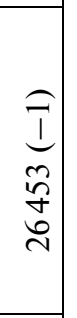 \\
\hline 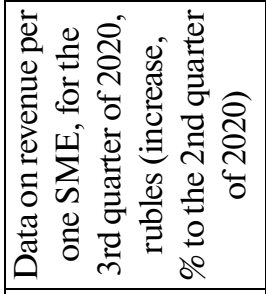 & 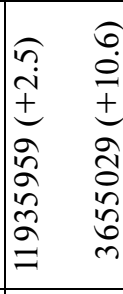 & 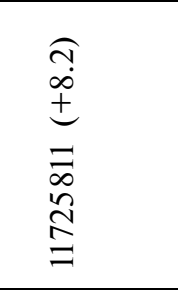 & 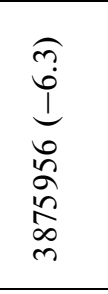 & 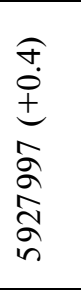 & 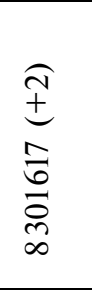 & 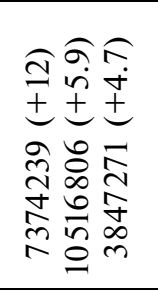 & 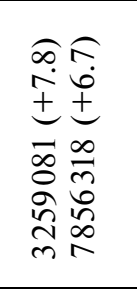 & 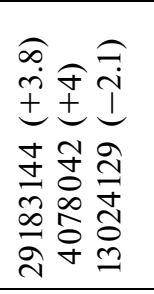 & 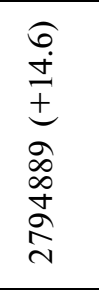 & 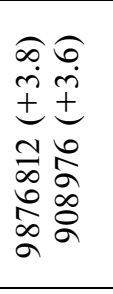 & 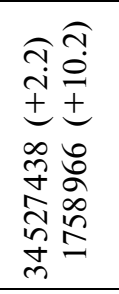 & 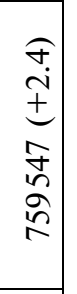 \\
\hline 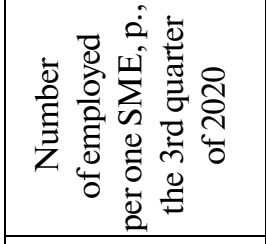 & in & $\stackrel{\infty}{+}$ & $\rightrightarrows$ & $\stackrel{9}{i}$ & 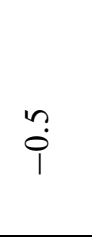 & $\stackrel{m}{i} \underset{i}{*}$ & $\stackrel{0}{+} \stackrel{?}{+} \stackrel{0}{0}$ & $\stackrel{\wp}{i}=$ & $\stackrel{+}{\circ}$ & n? & $\stackrel{\infty}{i}$ గ్ & $\begin{array}{l}0 \\
\dot{u} \\
i\end{array}$ \\
\hline 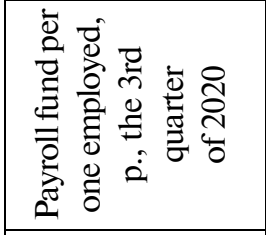 & $\hat{n}$ & $\stackrel{+}{\mathrm{I}}$ & $\hat{a}$ & $\hat{\infty}$ & $\stackrel{+}{\infty}$ & $\stackrel{n}{=} \hat{6}$ & 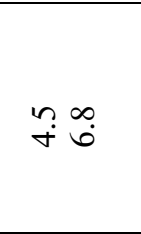 & orin & ஸ̣ & $\stackrel{\infty}{\sim} \underset{\sim}{\sim}$ & 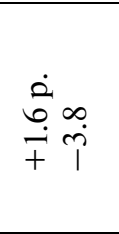 & $\stackrel{\infty}{-}$ \\
\hline 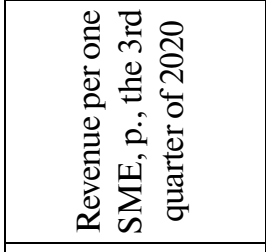 & $\overrightarrow{0}$ & ఠิ & $\stackrel{\infty}{i}$ & 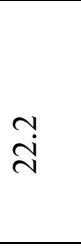 & $\stackrel{\infty}{-}$ & $\vec{a} \stackrel{\infty}{=} \stackrel{n}{0}$ & $\stackrel{\infty}{\oplus}$ & 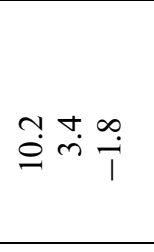 & $\exists$ & 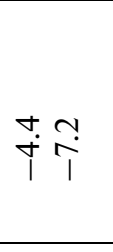 & $\stackrel{+}{-} \underset{1}{m}$ & $\stackrel{?}{i}$ \\
\hline 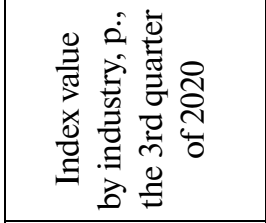 & $\stackrel{\sim}{=}$ & $\underset{\infty}{\infty}$ & $\infty$ & $\stackrel{0}{r}$ & $\stackrel{\infty}{0}^{\infty}$ & $\hat{\text { in }}$ in & $\underset{+}{\stackrel{\dot{D}}{\sim}} \underset{+}{+}$ & $\stackrel{\sim}{\sim} \stackrel{+}{\sim} \stackrel{i}{\sim}$ & $\stackrel{9}{-}$ & $\stackrel{0}{-} \stackrel{0}{0}$ & $\stackrel{0}{0}=$ & $\begin{array}{l}\infty \\
i \\
i\end{array}$ \\
\hline 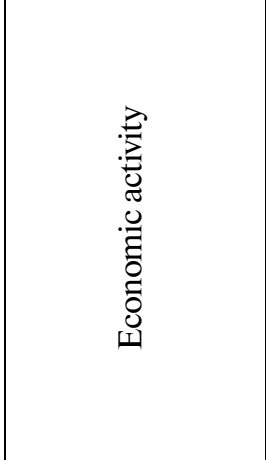 & 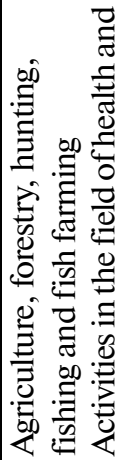 & 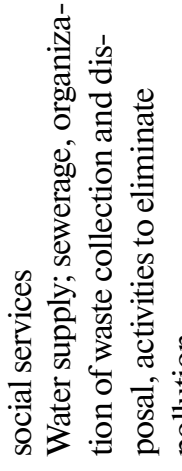 & 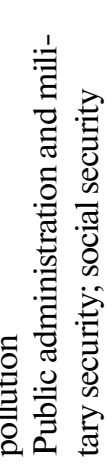 & 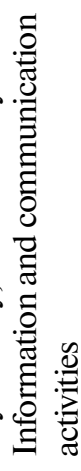 & 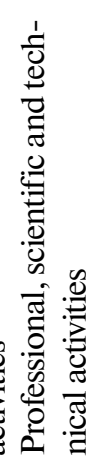 & 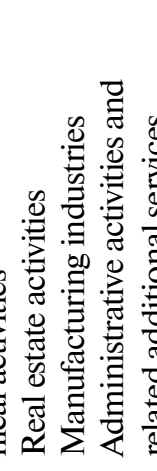 & 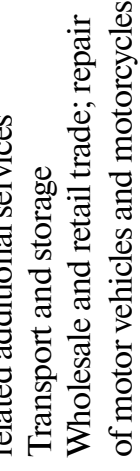 & 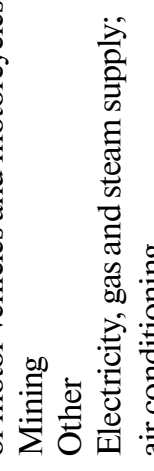 & 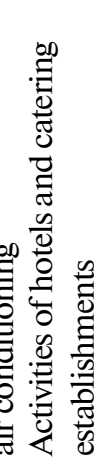 & 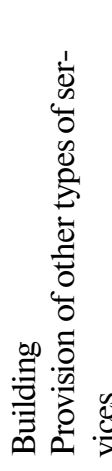 & 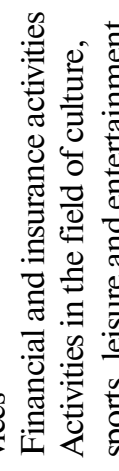 & 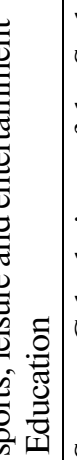 \\
\hline
\end{tabular}




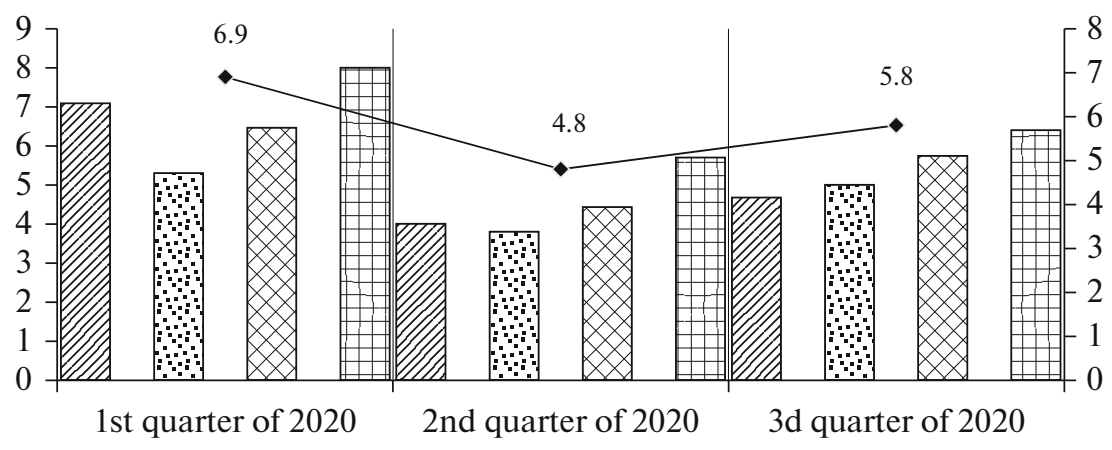

Fig. 2. Dynamics of the SME Growth Index by groups of regions: $\square$ 1st group; $\otimes 2$ 2nd group; 3 rd group; 4 th group; - final index (right scale).

and predict the state of the small and medium business sector.

-The Index makes it possible to assess and predict the development of the SME sector in the context of both regions and municipalities, and types of activity and size of enterprises.

-The Index can be used not only to assess the state of the SME sector, but also to justify the need to introduce additional support measures at the level of both the constituent entity of the Russian Federation and at the federal level.

-The Index allows receiving information on the turnover of companies applying special tax regimes, including the patent taxation system, UTII, as well as receiving information on the results of financial activities of companies at the end of the year ahead of schedule in January.

The main disadvantages of the Index:

-Despite the broad coverage of SMEs, the Index does not always allow assessing the reasons for the growth or decline in values in individual industries and regions (to clarify the dynamics, an in-depth analysis of the situation is required).

-A number of enterprises actually conduct activities that do not coincide with their chosen OKVED, as a result, the real picture in certain regions and types of economic activity may be distorted, which, however, is a limitation for other sources of administered data as well including tax data from the Federal Tax Service and Rosstat data (except for in-depth forms, for example, N1-services) based on the OKDP, etc.

-The Index does not take into account the possibility of transition of enterprises to the category of large or self-employed.

- The shadow economy remains outside the sample of the Index.

During the expert discussions, the participants were also asked to identify factors that could influence the dynamics of the Index values in regions and specific types of activity. Thus, the participants in the expert meetings linked the Index indicators in their regions with the following factors:

-Active implementation of measures to support SMEs at the level of a constituent entity of the Russian Federation (for example, Moscow, Volgograd, Vladimir, Sverdlovsk oblasts, etc.).

- Regional policy and policy of municipalities aimed at updating fixed assets, construction of new buildings and structures and infrastructure development (for example, in Kursk oblast in 2020, a program was launched to update urban facades, as a result, the SMEs performing activities in the field of architecture and engineering design in the region demonstrated a significant increase in all indicators of the Index: revenue per one SME was +50 p., payroll fund per one employed +17.9 p., number of employees per one SME +26.9 p.).

-Dependence of the indicators of certain industries on the state order (including the state defense order): for example, in Tula oblast, as a result of the change in the conditions of the state defense order, there was a decrease in revenue from SMEs in the sector of production of machinery and equipment not included in other groups.

-Entry into the market of new large enterprises and the redistribution of government support (for example, in Kursk oblast, the opening of new production facilities by Miratorg company led to a decrease in the revenue of SME entities in the crop and livestock sector).

- Reduction of nonproduction costs (advertising, marketing) and, as a result, a reduction in revenue, payroll fund and employment of enterprises conducting advertising activities and market research.

-A drop in demand for a number of goods and services (beauty salons, entertainment, accounting services, etc.) associated with the pandemic and the general change in the economic situation.

-The structure of the economy and individual sectors in a region in the context of a pandemic (in some regions, SMEs performing activities in the field of health showed growth due to the growing demand for 
services related to medical tests, and in others a decrease, for example, in Tula oblast, where in the structure of this sector of the economy a significant share is made up of private dental clinics, in respect of which restrictive measures were carried out).

-Digital transformation of small and medium businesses (for example, in Sverdlovsk oblast, small and medium clothing manufacturing enterprises demonstrated growth in all three indicators of the Index, which is associated with the entry of a number of enterprises to the Wildberries Internet platform).

- Particular cases of transition of SME entities to the category of large enterprises, which led to their exclusion from the register of SMEs and the Index sample.

At the same time, the factors indicated by the participants in the expert discussions require additional verification and checks, which will be implemented in further studies as part of the development of the Index.

Among the key areas for the development of this tool are the following:

- Supplementing the Index with the results of expert surveys in the constituent entities of the Russian Federation in order to verify and clarify the reasons for the change in the Index indicators in the territory of the constituent entity of the Russian Federation (applied support measures, changes in the parameters of taxes and fees, regulatory, sanitary and epidemiological restrictions, etc.).

- Supplementing the Index data with operational data from other banks, the Federal Tax Service (including tax calculator data, data on the tax burden on enterprises, profitability, data on taxes and fees paid, data on the self-employed) and the Bank of Russia (data on the debt burden on the SME sector).

-Accounting the consumer price index as part of assessing the dynamics of the Index indicators.

-Accounting of receipts of borrowed funds to the settlement accounts of SME entities.

- Evaluation of the sample obtained on the basis of the data of PAO Sberbank and its comparison with the data of the Federal Tax Service.

- Conducting an additional cycle of studies on the impact of federal and regional government support measures, tax incentives on the results of the development of the SME sector in the constituent entities of the Russian Federation and in certain types of economic activity.

Taking into account plans for further development, the Index can become an important tool not only for monitoring and forecasting the state of the SME sector in the constituent entities of the Russian Federation, but also a tool for assessing the effectiveness of financial and tax measures to support SME entities and justifying the need to introduce additional federal, regional and municipal support measures.
As one of the applied tools of the Index, the creation of situational centers for the development of SMEs in the constituent entities of the Russian Federation (hereinafter, the situational center) is being worked out.

During the discussions, a number of representatives of state authorities in the constituent entities of the Russian Federation announced their readiness to take part in a detailed pilot survey of the state of the SME sector and to provide assistance in supplementing the data used to calculate the Index with data from other banks serving SMEs and data of the Federal Tax Service.

In fact, a detailed pilot survey of the state of the SME sector in a constituent entity of the Russian Federation can become the basis for the activities of the situation center, the key goal of which is to ensure the development of the SME sector, including its contribution to the gross regional product and employment. The activities of the situational center can cover both priority sectors (for example, the "economy of simple things" sector or high-tech companies), and the entire structure of the economy of a constituent entity of the Russian Federation.

The creation of a situational center for the development of SMEs will allow:

- Monitoring the state of the SME sector in terms of municipalities, types of activity, size of business (including on the basis of indicators of the dynamics of revenue per one SME, payroll per one employed in the SME sector and the number of employees per one SME).

-Determining the key sectors of the economy, based on the priorities of state policy, and to develop measures of state support necessary to ensure their development.

- Evaluating the effects of the implemented federal and regional measures, as well as determining the directions and effects of the necessary adjustments to the current state policy.

As a result, the use of these data can create new opportunities for high-quality and "smart" state policy aimed at developing the small and medium business sector at the level of both the federal and the constituent entities of the Federation, and will also make it possible to develop and correct the applied support measures depending on their effectiveness and impact on the small and medium business sector.

\section{ACKNOWLEGMENTS}

The article is based on a report read at the International Conference on Macroeconomic Analysis and Forecasting dedicated to the 85th anniversary of the birth of Academician V.V. Ivanter and Yu.V. Yaremenko, as well as the 35th anniversary of the founding of the Institute of Economic Forecasting of the Russian Academy of Sciences. 


\section{REFERENCES}

1. Order of the Government of the Russian Federation of June 2, 2016 No. 1083-r "On the Strategy for the Development of Small and Medium-Sized Businesses in the Russian Federation for the Period up to 2030 and the Action Plan ("Road Map") for Its Implementation." http://www.consultant.ru/.

2. Decree of the President of the Russian Federation of July 21, 2020 No. 474 "On the National Development Goals of the Russian Federation for the period up to 2030.” http://www.consultant.ru/.

3. Report of the Commissioner under the President of the Russian Federation for the Protection of the Rights of Entrepreneurs to the President of the Russian Federation2020. Register of Systemic Problems of Russian Business. http://doklad.ombudsmanbiz.ru/2020/3.pdf. Accessed December 7, 2020.

4. M. A. Abramova, S. E. Dubova, O. V. Zakharova, M. V. Ershov, and O. I. Lavrushin, "On the main directions of the unified state monetary policy for 2019 and the period of 2020 and 2021: Opinions of experts of the Financial University," Ekon., Nalogi, Pravo 12 (1), 6-19 (2019).

5. D. E. Shilkov and A. L. Savatyugin, Report on the Results of the Expert-Analytical Event "Assessment of the State of Guarantee Support and Microfinance of Small and Medium-Sized Businesses in the Russian Federation in 2015-2018 and the First Half of 2019" (Accounts Chamber of the Russian Federation, 2019). https://Ach.Gov.Ru/Upload/Iblock/60a/60a1e40f2fe53797e18a3a99e5eb5b27.pdf.

6. A. O. Alekhnovich and K. M. Nikitin, "'Smart' tax system,” Nauchn. Tr. Vol'nogo Ekon. O-va. Ross. 209 (1), 25-44 (2018).

7. Key Aspects of the Program of Social and Economic Development of Russia until 2025 "Strategy of Growth:" Scientific Report (Stolypin Institute for the Economics of Growth, 2017). https://stolypin.institute/wp-content/uploads/2017/11/nauchnyy-doklad strategiya-rosta_16.11.17.pdf. Accessed December 7, 2020.

8. Q. Jia, Y. Guo, J. Wang, and S. Barnes, "Big Data analytics in the fight against major public health incidents (including COVID-19): A conceptual framework," Int. J. Environ. Res. Public Health 17 (17) (2020). https://www.mdpi.com/1660-4601/17/17/6161. Accessed December 7, 2020.

9. N. Bragazzi, G. Damiani, and M. Behzadifar, "How Big Data and artificial intelligence can help better manage the COVID-19 pandemic," Int. J. Environ. Res. Public Health 17 (9) (2020). https://doi.org/10.3390/ijerph17093176

10. Yu. V. Irkhin, "Classic and digital approaches in public administration in the context of the coronavirus pandemic," Ars Adm. 12 (3), 367-384 (2020). https://doi.org/10.17072/2218-9173-2020-3-367-384

11. H. Pinglin, N. Hanlu, S. Zhe, and L. Tao, "Accounting Index of COVID-19 impact on Chinese industries: A case study using big data portrait analysis," Emerging Mark. Finance Trade 56 (10), 2332-2349 (2020). https://doi.org/10.1080/1540496X.2020.1785866

12. J. Sheng, J. Amankwah-Amoah, Z. Khan, and X. Wang, "COVID-19 pandemic in the new era of big data analytics: Methodological innovations and future research directions,” Br. J. Manage. (2020). https://doi.org/10.1111/1467-8551.12441

13. N. Henke, A. Puri, and T. Saleh, Accelerating Analytics to Navigate COVID-19 and the Next Normal (McKinsey \& Company, 2020). https://www.mckinsey.com/business-functions/mckinsey-analytics/our-insights/accelerating-analytics-to-navigate-covid-19-andthe-next-normal. Accessed July 12, 2020.

14. R. Munne, Big Data in the Public Sector. New Horizons for a Data-Driven Economy (Springer, Cham, 2016), pp. 195-208. https://doi.org/10.1007/978-3-319-21569-3_11

15. A. G. Aganbegyan, A. N. Klepach, B. N. Porfiryev, M. N. Uzyakov, and A. A. Shirov, "Post-pandemic recovery: The Russian economy and the transition to sustainable social and economic development," Stud. Russ. Econ. Dev. 31, 599-605 (2020).

16. I. N. Paramonova, "Priority directions of the state policy of counteraction to the shadow economy," Ekon., Finansy, No. 18, 72-75 (2020).

17. V. V. Gromov and N. S. Milogolov, "Recommendations for supplementing measures to support small and medium-sized businesses in a pandemic in terms of reducing the tax burden on labor (for the payment of insurance premiums),” Ekon. Razvit. Ross. 27 (5), 83-89 (2020).

Translated by S. Avodkova 